\title{
PERUBAHAN LUAS TUTUPAN LAHAN PADA AREAL HUTAN LINDUNG GUNUNG SIRIMAU KOTA AMBON
}

\section{CHANGE IN FOREST LAND COVER TOWARDS ABSORPTION OF $\mathrm{CO}_{2}$ GAS IN PROTECTED FOREST MOUNTAIN SIRIMAU AMBON CITY}

\author{
Oleh \\ Yulianus Dominggus Komul ${ }^{1)^{*}}$, Merlin Renny Sitanala ${ }^{2)}$ \\ ${ }^{1)}$ Jurusan Kehutanan, Fakultas Pertanian, Universitas Pattimura, Ambon, 97233 \\ ${ }^{2)}$ Jurusan Kehutanan, Fakultas Pertanian, Universitas Pattimura, Ambon, 97233
}

Email : yulianuskomul88@gmail.com

\begin{tabular}{l|l} 
Diterima 18 Januari 2021 & Disetujui 10 Maret 2021
\end{tabular}

\begin{abstract}
Abstrak
Tujuan penelitian ini adalah Mengetahui perubahan tutupan lahan hutan Lindung Gunung Sirimau Kota Ambon yang di analisis dari Tahun 1990, 2000, 2006, 2011 dan 2015. Penelitian ini dilakukan dengan menggunakan metode analitik dimana citra satelit landsat dari 5 tahun rekaman berbeda yaitu tahun 1990, 2000 dan 2006 , 2011 dan 2015 diinterpretasi secara digital melalui klasifikasi supervised Setelah itu dilakukan pemetaan dengan menggunakan ArGIS untuk menganalisis perubahan tutupan lahan hutanya dengan data pendukung dari Balai Pemantauan kawasan Hutan Wilayah IX Ambon yang telah dioleh dengan menggunakan ArGIS menjadi data primer. Sedangkan untuk analisis data menggunakan metode analisis digital atau metode peluang maksimum. Hasil penelitian menunjukan perubahan tutupan lahan Tahun 2000, 2006 dan 2011 dari daerah lahan hutan menjadi lahan pertanian dan kemudian pada Tahun 2015 daerah lahan pertanian dialihfungsikan menjadi daerah pemukiman. Penambahan daerah non hutan (Pemukiman) disepanjang kawasan dusun Toisapu dan Desa Soya sampai dengan Tahun 2015 untuk daerah pemukiman mencapai 16,997 Ha dengan rata-rata pertambahan tiap tahun sebesar 70,59 km2.
\end{abstract}

Kata kunci: Perubahan Tutupan Lahan Hutan, Hutan Lindung Gunung Sirimau.

\begin{abstract}
The purpose of this research was to determine changes in forest cover of Mount Sirimau Protected Forest in Ambon City which have been analyzed since 1990, 2000, 2006, 2011 and 2015. This research was conducted using analytical methods where satellite imagery of 5 different years in 1990, 2000 and 2006 recording years, 2011 and 2015 were interpreted digitally through supervised classification. After the interpretation, the mapping was carried out using ArGIS to analyze changes in forest cover. It is supported by the data from the Forest Monitoring Center of Ambon Area IX that had been obtained using ArGIS into primary data. The data were analyzed by using the digital analysis method or the maximum opportunity method. The results showed changes in land cover in 2000, 2006 and 2011 from areas of forest become agricultural land and in 2015 the area of agricultural land was changed into settlements areas. The augmentation of non-forest areas (Settlements) along the Toisapu hamlet and Soya villages up to 2015 for residential areas has reached 16,997 Ha with an average annual increase of $70.59 \mathrm{~km} 2$.
\end{abstract}

Keywords : Change in Forest Land Cover, Sirimau Mountain Protection Forest

DOI:10.30598/jhppk.2021.5.1.68

ISSN ONLINE: 2621-8798 


\section{PENDAHULUAN}

Perubahan Tutupan Lahan hutan yang disebabkan alihfungsi lahan untuk berbagai kepentingan merupakan ancaman serius bagi keberlangsungan ekosistem maupun manusia, hal ini akan semakin diperparah jika kebijakan tersebut diterapkan pada kawasan hutan yang telah ditetapkan oleh pemerintah menurut fungsinya sebagai perlindungan sistem penyangga kehidupan untuk mengatur tata air, mencegah banjir, mengendalikan erosi, mencegah intrusi air laut, dan memelihara kesuburan tanah, (UU No. 5 Tahun 1967), maka secara tidak langsung dalam kurun waktu tertentu akan mengalami degradasi dan deforestasi yang mengancam keanekaragaman dan endemisitas jenis flora dan fauna terutama pada pulau-pulau kecil seperti di Provinsi Maluku.

Hutan Lindung Gunung Sirimau secara administratif sesuai dengan Peraturan Kota Ambon Nomor 2 Tahun 2006 berada pada 3

\section{METODE PENELITIAN}

Penelitian dilaksanakan selama 2 bulan (September - Oktober) Tahun 2015 di Kawasan Hutan Lindung Gunung Sirimau yang juga disesuaikan dengan data penyerapan karbon (tiga) Wilayah Kecamatan yaitu Kecamatan Sirimau (Petuanan Desa Soya dan STAIN-Air Besar Desa Batumerah), Kecamatan Teluk Ambon Baguala (Petuanan Desa Passo dan Desa Halong), dan Kecamatan Leitimur Selatan (Petuanan Desa Hutumuri, Desa Rutong, Desa Lehari dan Desa Hukurila). Yang ditetapkan sesuai surat keputusan Menteri Kehutanan Nomor: 10327/Kpts-II/2002 dengan luas 3,449 Ha. (Anonim, 2013)

Analisis perubahan tutupan lahan pada kawasan hutan Lindung Gunung Sirimau Kota Ambon dibuat dengan mengacu pada data perubahan yang diperoleh dari Balai Pemantauan Kawasan Hutan Wilayah IX Maluku yang disesuaikan dengan data perubahan kandungan biomassa dan karbon simpanan pada PSP Hutan Negeri Soya Kota Ambon dan agar dapat memberikan nilai pembanding untuk perubahan yang terjadi dan mengestimasi perubahan yang akan terjadi untuk waktu mendatang.

pada Lokasi PSP (Plot Sampling Parmanent) yang telah ditetapkan pembangunannya mulai Tahun 2012 sebagai lokasi penelitian yang berada pada petuanan hutan Negeri Soya Kota Ambon. 


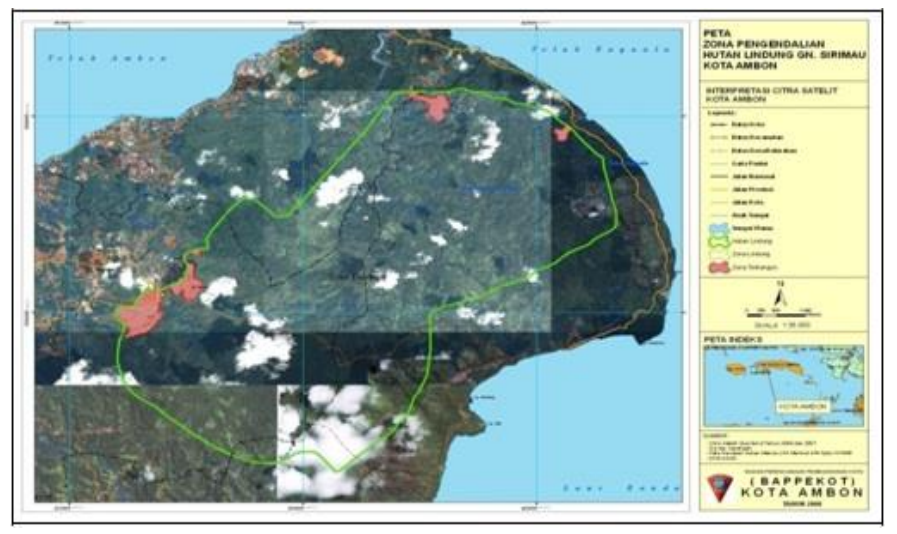

Gambar 1. Peta Lokasi Penelitian (Lelolltery H.2020)

Penelitian ini dilakukan dengan menggunakan metode analitik dimana citra satelit landsat dari 5 tahun rekaman yang berbeda yaitu tahun 1990, 2000 dan 2006, 2011 dan 2015 diinterpretasi secara digital melalui klasifikasi supervised Setelah itu dilakukan pemetaan dengan menggunakan ArGIS untuk menganalisis perubahan tutupan lahan hutanya. Proses ini diawali dengan Pra Processing citra digital yaitu dengan cara mengisi citra yang dijadikan master dengan citra pengisi yang bisa saja keduanya memiliki stripping (banding) namun pada lokasi yang berbeda, sehingga dapat

Data yang digunakan berupa data pendukung terdiri atas data Citra Allos, Landsat 7 dan Landsat 8 daerah liputan pulau Ambon, dan shp (shapefile) dari Peta rupa bumi Indonesia Provinsi Maluku, skala 1: 250.000, peta administrasi Pulau Ambon Skala 1 :

Untuk analisis perubahan tutupan lahan dapat dilakukan dengan mengacu pada Matriks diagram alur proses analisis perubahan tutupan saling mengisi; melakukan koreksi geometrik (Rektifikasi) maupun radiometrik citra (Radiometric enhanchment). Pengolahan citra digital untuk citra landsat 8 dilakukan melalui penyiapan citra mozaik, pembuatan citra komposit dan melakukan klasifikasi visual (on screen digitation) dan klasifikasi digital untuk memperoleh kelas penutup lahan setiap tahun (1990, 2000 dan 2006, 2011 dan 2015) yang data pendukungnya diperoleh dari Balai Pemantauan kawasan Hutan Wilayah IX Ambon.

250.000. Peta penutupan lahan Tahun 1990, 2000, 2006, 2011 dan 2015, skala 1 : 50.000; dan peta penetapan wilayah KPH provinsi Maluku tahun 2010 , skala $1: 250.000$, dan peta batas kawasan hutan lindung sirimau, skala 1 : 100.000

lahan yang disajikan dalam bentuk gambar berikut: 


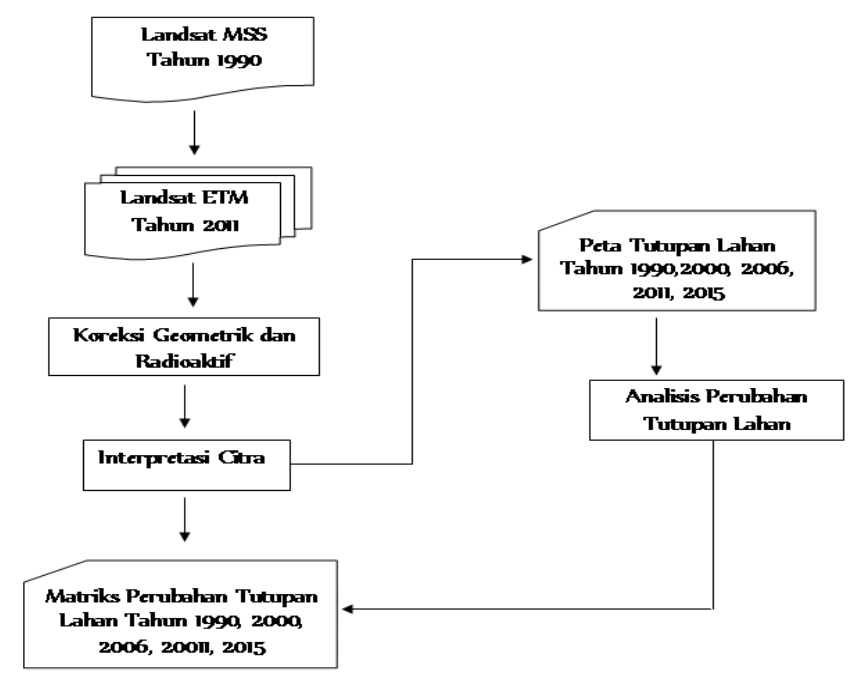

Gambar 2. Matriks Alur Analisis Perubahan tutupan Lahan.

Berdasarkan matriks diagram Alir Perubahan yang disajikan, dapat diuraikan beberapa langkah penting dalam menghasilkan peta tutupan lahan yang menggunakan program

Dalam penelitian ini pula data yang diperoleh dianalisis dengan menggunakan metode analisis digital atau metode peluang maksimum (Maximum likelihood classifier). Pada metode ini terdapat pertimbangan berbagai faktor, diantaranya adalah peluang dari suatu piksel untuk dikelaskan kedalam kelas atau kategori tertentu (Lilesand TM, Kiefer RW 1990). Dalam klasifikasi diperlukan suatu penciri kelas. Penciri kelas ini adalah satu set data yang diperoleh dari suatu training area,

\section{HASIL DAN PEMBAHASAN}

\section{Perhitungan Perubahan Tutupan Lahan Hutan.}

\section{Tutupan Lahan Tahun 1990.}

Pada Tahun 1990, hasil identifikasi memperlihatkan tutupan lahan Kawasan Hutan Lindung Gunung Sirimau dengan pengolahan data citra Allos, Landsat 7 dan Landsat 8 yang digunakan sebagai pembanding, diketahui
ArcView GIS10.1. Beberapa hal penting yang diperhatikan adalah; Digitasi objek, analisis GIS, Editing peta dan atribut hasil overlay dan penampilan peta (Dwiprabowo 2011). ruang feature (feature space) atau klaster. Jumlah piksel yang harus diambil untuk training area pada masing - masing kelas adalah sebanyak jumlah band yang digunakan plus satu (N+1) (Jaya 2010) Hasil analisis digital pada citra tahun 1990, 2000, 2006, 2011 dan 2015 yang merupakan data dalam bentuk raster yang kemudian diubah dalam bentuk vektor dan dilakukan overlay untuk menilai perubahan penutup lahan melalui analisis spasial pada SIG (Pattilouw I $d k k$. 2019).

kawasan Hutan Lindung Sirimau Kota Ambon mempunyai luas sebesar 3239,67 Ha luas areal Hutan Lindung Sirimau dibagi menjadi empat daerah yang dengan luasan identifikasi terbagi sebagai atas belukar, Hutan lahan kering primer, hutan lahan kering sekunder dan hutan lahan 
kering campuran yang masing-masing luasannya dapat dilihat pada tabel berikut:

Tabel 1. Luas Daerah Tutupan Lahan Tahun 1990

\begin{tabular}{|c|c|c|}
\hline Areal & Daerah & $\begin{array}{c}\text { Luas Daerah } \\
\text { (Ha) }\end{array}$ \\
\hline & Belukar & 1322,22 \\
\hline Hutan Lindung & Hutan Lahan Kering Primer & 300,12 \\
\hline \multirow[t]{2}{*}{ Srimau } & Hutan Lahan Kering Sekunder & 882,53 \\
\hline & Hutan Lahan Kering Campuran & 374,79 \\
\hline
\end{tabular}

Ket : Hasil analisis data, 2015

Berdasarkan data luasan daerah tutupan lindung Gunung Sirimau pada Tahun 1990, lahan Tahun 1990 yang disajikan maka dapat sehingga memiliki potensi tejadinya perubahan diketahui bahwa belukar merupakan daerah tutupan lahan diwaktu sesudahnya sangat besar. yang memiliki luasan terbesar dibandingkan Kenampakan untuk perubahan yang terjadi pada dengan daerah lainnya pada kawasan hutan Tahun 1990 telihat pada gambar 3.

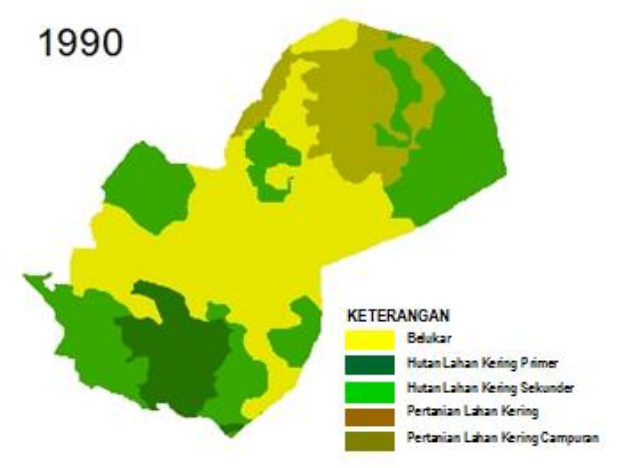

Gambar 3. Identifikasi Tutupan Lahan Tahun 1990.

\section{Tutupan Lahan Tahun 2000, 2006 dan} 2011.

Pada Tahun 2011 tutupan lahan hasil identifikasi mengalami perubahan jika dibandingkan pada Tahun 1990. Perubahan ditandai dengan kehadiran lima warna yang mengindikasi terdapat 5 daerah tutupan yang telah mengalami perubahan. Perubahan yang terjadi ditandai dengan berkurangnya luas kawasan hutan lahan kering sekunder dari 88,53 Ha pada Tahun 1990 menjadi 825,26 Ha pada Tahun 2000. Perubahan yang terjadi disebabkan karena konversi lahan hutan oleh masyarakat menjadi daerah kawasan pertanian diantaranya pertanian lahan kering dan pertanian lahan kering campuran (warna kuning dan hijau pada peta). 
Tabel 2. Luas Daerah Tutupan Lahan Tahun 2000, 2006 dan 2011

\begin{tabular}{llr}
\hline \multicolumn{1}{c}{ Areal } & \multicolumn{1}{c}{ Daerah } & \multicolumn{1}{c}{ Luas Daerah } \\
& & $($ Ha) \\
\hline \multirow{4}{*}{ Hutan Lindung } & 1322,22 \\
Srimau & Belukar & 300,12 \\
& Hutan Lahan Kering Primer & 825,26 \\
& Hutan Lahan Kering Sekunder & 374,79 \\
& Pertanian Lahan Kering & 734,79 \\
\hline & Pertanian Lahan Kering Campuran & 3239,667 \\
\hline
\end{tabular}

Ket : Hasil analisis data, 2015

Daerah Pertanian lahan kering dan dilakukan dengan pembanding berupa citra pertanian lahan kering campuran berada pada Allos, Landsat7 dan Landsat8, ternyata dari kawasan Toisapu dan kawasan Rutong dan Tahun 2000 sampai 2011 tidak mengalami Hutumury. Daerah tipe tutupan hutan lahan perubahan baik luasan maupun tipe tutupannya kering primer merupakan daerah yang sehingga dapat dikatakan kondisi daerah atau ditetapkan sebagai daerah penelitian. Hasil lokasi yang terdapat pula lokasi penelitian, identifikasi yang dilakukan pada Tahun 1990, keberadaan vegetasinya masih tetap terjaga.

2000, 2006 dan 2011 melalui tafsiran yang
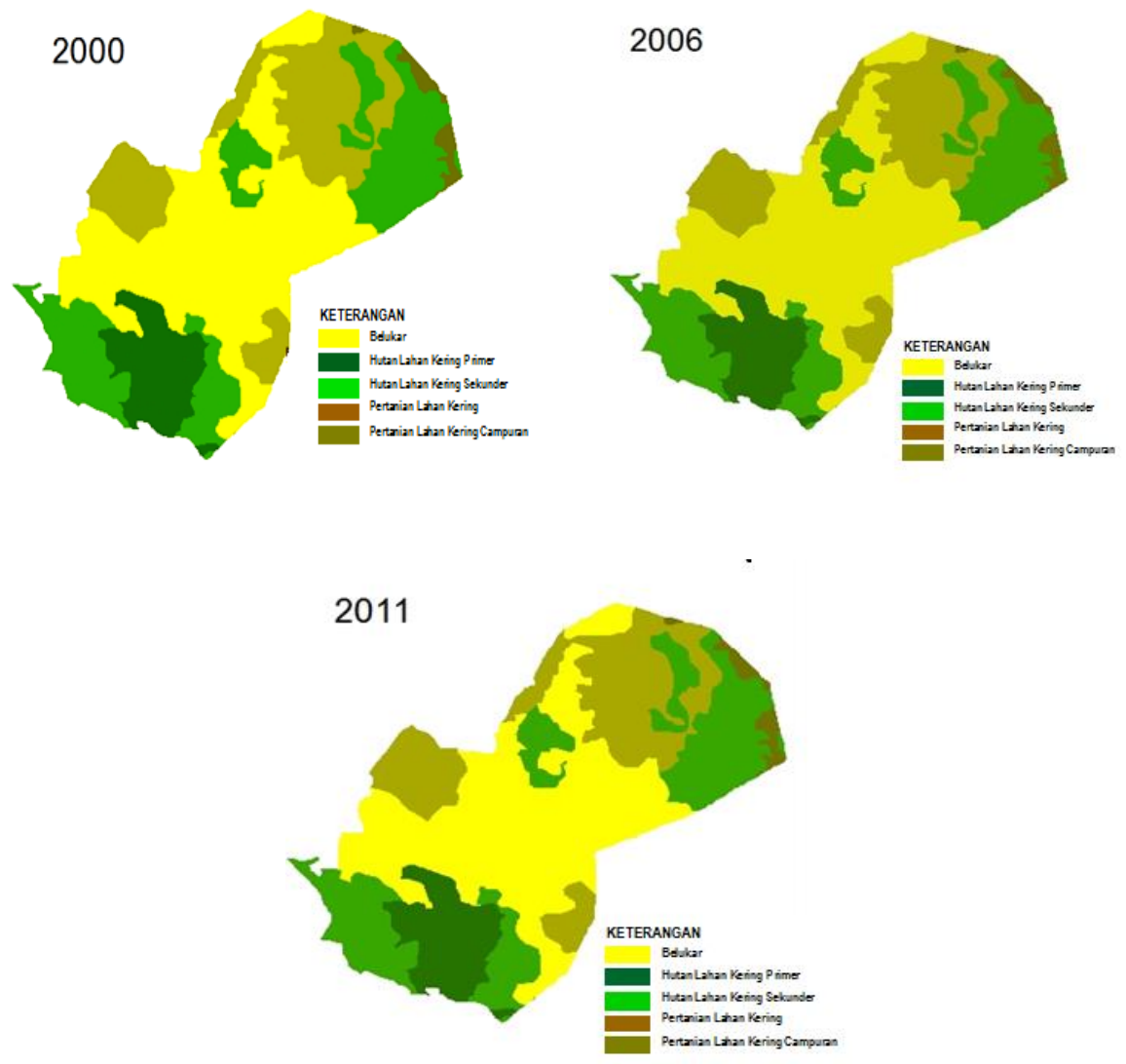

Gambar 4. Identifikasi Tutupan Lahan Tahun 2000, 2006 dan 2011. 


\section{Perubahan Tutupan Lahan Tahun 2015}

Pada Tahun 2015, terjadi penambahan daerah non hutan. penambahan area tersebut adalah pembangunan pemukiman dan perumahan penduduk yang terjadi di sepanjang pesisir HLGS. Daerah-daerah yang mengalami perubahan diantaranya Pada kawasan hutan Toisapu dan Negeri Soya. Peningkatan jumlah penduduk yang dibaringi dengan peningkatan kebutuhan akan sumberdaya alam dan kebutuhan akan hidup memaksa manusia untuk berusaha memenuhi segala bentuk kebutuhan sehingga kesejahteraan dan kemandirian merupakan tujuan hidup. Hal demikian merupakan salah satu tjuan dengan cara yang ditempuh guna menjawab permasalahan yang dialami.

Tabel 3. Luas Daerah Tutupan Lahan Tahun 2015

\begin{tabular}{llr}
\hline \multicolumn{1}{c}{ Areal } & \multicolumn{1}{c}{ Daerah } & Luas Daerah (Ha) \\
\hline & Belukar & 1350,52 \\
& Hutan Lahan Kering Primer & 300,12 \\
Hutan & Hutan Lahan Kering Sekunder & 784,12 \\
Lindung & Pertanian Lahan Kering & 57,28 \\
Sirimau & Pertanian Lahan Kering Campuran & 730,63 \\
& Pemukiman & 16,99 \\
\hline & & 3239,667 \\
\hline
\end{tabular}

Ket : Hasil analisis data, 2015

Laju perubahan tutupan lahan untuk sekunder 784,12 Ha, hutan lahan kering primer areal pemukiman dan perladangan dilihat dari tidak mengalami perubahan dari tahun 1990 luasan yang diperoleh. untuk daerah pemukiman 2015 yaitu dengan luasan 300,12 ha. Sedangkan luasannya mencapai 16,99 Ha, pertanian lahan untuk belukar menempati luasan tertinggi yaitu kering campuran luasan 730,63 Ha, pertanian 1350,52 Ha. lahan kering 57,28 Ha, hutan lahan kering

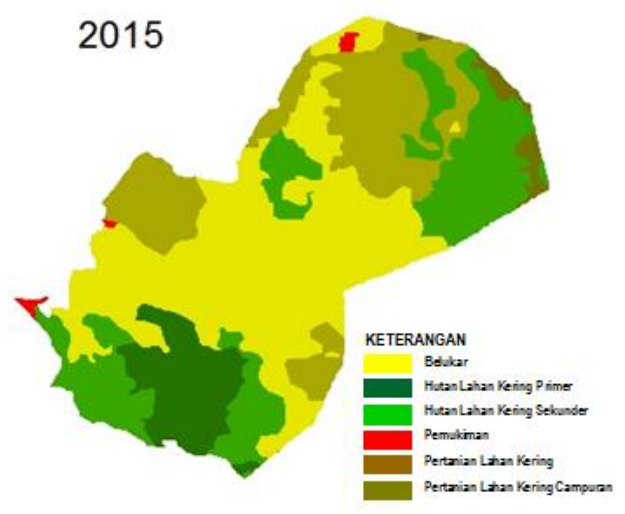

Gambar 5. Identifikasi Tutupan Lahan Tahun 2015 
4. Perubahan Tutupan Lahan Tahun 1990, 2000, 2006 dan 2015

Tutupan lahan pada kawasan hutan lindung Sirimau terutama pada lokasi penelitian yang penggunaannya dari Tahun 1990 sampai dengan Tahun 2015 secara langsung mengalami perubahan walaupun dalam jangka waktu yang lama (25 tahun).

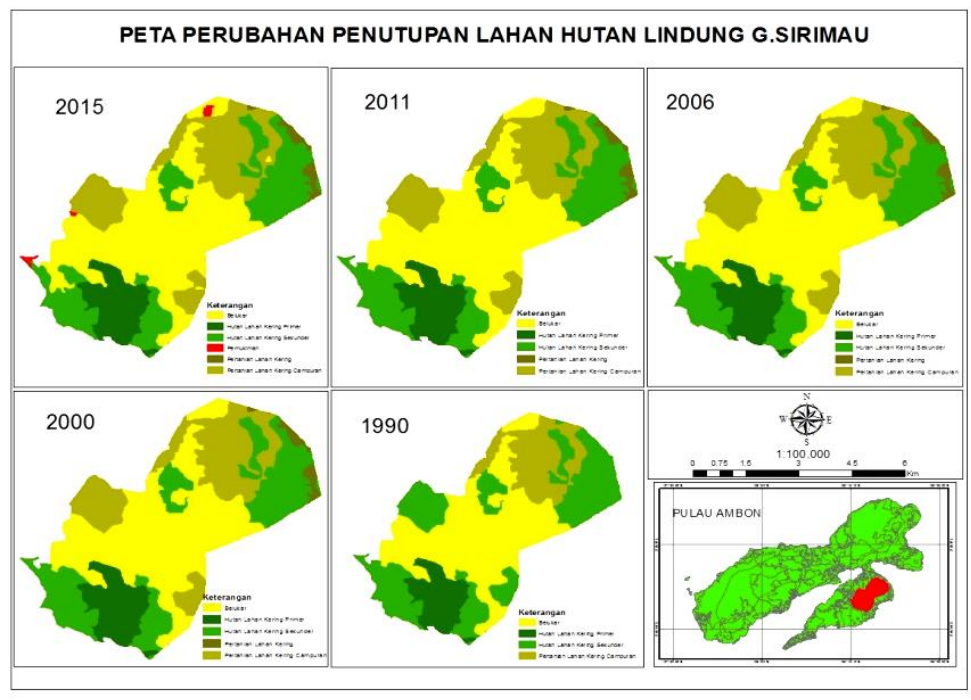

Gambar 6. Identifikasi Tutupan Lahan Tahun 1990, 2000, 2006, 2011 dan 2015

Perubahan yang terjadi yaitu pada Tahun 2000, 2006 dan 2011 dari daerah lahan hutan menjadi lahan pertanian dan kemudian pada Tahun 2015 daerah lahan pertanian diahlifungsikan menjadi daerah pemukiman. Daerah pemukiman ini merupakan salah salah satu contoh dariperubahan alih fungsi hutan menjadi area aktifitas manusia yang terjadi di Maluku. Penambahan daerah non hutan (Pemukiman) disepanjang kawasan Toisapu dan Perubahan yang terjadi terhitung dari Tahun 2011-2015 secara keseluruhan di Indonesia mengalami penurunan terutaman untuk indeks tutupan hutan. Kondisi tutupan hutan yang semakin menurun tersebut, diikuti dengan sebaran dan frekuensi kejadian bencana banjir, tanah longsor, kekeringan dan kebakaran hutan dan lahan. Untuk memperbaiki kondisi ini, Rencana Pembangunan Jangka Menengah
Negeri Soya sampai dengan Tahun 2015, untuk daerah pemukiman mencapai 16,997 Ha dengan rata-ratapertambahan tiap tahun sebesar 70,59 km2). Hutan sekunder merupakan kawasan hutan yang tumbuh kembali setelah terjadi penebangan. Tampak hutan sekunder pada citra yaitu hijau tua, struktur vegetasinya jarang hingga rapat, tekstunya halus hingga kasar, dan pola yang tidak teratur. (Christomus Bode, dkk, 2015)

Nasional (RPJMN) 2015-2019 menetapkan sasaran yang akan dicapai yakni indeks tutupan lahan meningkat dari nilai 59 menjadi 62. Untuk mencapai sasaran tersebut, perlunya upaya meningkatkan kualitas tutupan lahan secara terkoordinasi antara Pemerintah, Pemerintah Provinsi, Pemerintah Kabupaten/Kota, komponen masyarakat dan dunia usaha (Rochmayanto. dkk. 2014). 


\section{KESIMPULAN}

Berdasarkan penelitian yang telah dihasilkan, disimpulkan bahwa; Tutupan hutan/lahan pada kawasan hutan lindung Gunung Sirimau dengan penggunaan peta tutupan Tahun 1990, 2000, 2006, 2011 dan 2015 dalam jangka waktu yang lama (25 tahun), perubahan terjadi pada Tahun 2000 sampai dengan 2011 dari daerah lahan hutan sekunder menjadi lahan pertanian kering dan lahan

\section{DAFTAR PUSTAKA}

Andhono Yekti, dkk. 2013. Analisis Perubahan Tutupan Lahan DAS Citanduy Dengan Metode Penginderaan Jauh. Jurnal Geodesi Undip. Semarang.

Anonim. 2012. Laporan Akhir Pembangunan PSP (Plot Sampling Permanent) pada berbagai tipe hutan dimaluku (Forest Carbon Partnership Facility (FCPF) REDD+ Readiness Preparation oleh Program Studi Manajemen Hutan. Program Pascasarjana Universitas Patimura. Ambon.

--, 2013. Monitoring PSP (Plot Sampling Permanent) untuk mendukung system MRV stok carbon hutan dimaluku. Program Studi Manajemen Hutan, program Pascasarjana Universitas. Ambon.

Christomus Bode, dkk, 2015. Analisis Perubahan Tutupan Lahan Di Taman Hutan Raya Gunung Tumpa Menggunakan Sistem Informasi Geografis. Jurnal Cocos Universitas Sam Ratulangi Manado, hal $1-10$.

Danang Arif Maullana dan Arief Darmawan. 2014. Perubahan Penutupan Lahan Di Taman Nasional Way Kambas (Land Cover Changes In Way Kambas National Park). Jurnal Sylva Lestari. 2.1: $87-93$. pertanian campuran. Tahun 2015 daerah lahan pertanian diahlifungsikan menjadi daerah pemukiman. Penambahan daerah non hutan (Pemukiman) dengan luasan 16,997 Ha pada negeri Toisapu dan Soya kota. Jika diestimasi perubahan untuk selang waktu yang akan datang maka perubahan hanya akan terjadi pada daerah pesisir namun untuk kawasan Hutan Lindung Gunung Sirimau akan tetap terjaga tutupan lahan hutannya.

Dwi Prabowo. Dkk. 2011. Dinamika Tutupan Lahan, Pengaruh Faktor Ekonomi, Editor Irsal Las, Rahayu Y. Penerbit PT Kanisius Jogjakarta.

Indrajaya Y. 2013. Cadangan Karbon Hutan Lindung Long Ketrok Di Kabupaten Malinau, Kalimantan Timur Untuk Mendukung Mekanisme REDD+ Balai Penelitian Teknologi Agroforestry. Ciamis. Banjar.

Lelloltery. H. Hitipeuw J. Ch, dan Sahureka M. 2020. Strategi Pengembangan Ekowisata Berbasis Masyarakat Di Hutan Lindung Gunung Sirimau Kota Ambon. Jurnal Hutan Tropis $8: 23-35$.

Pattimahu D. V. 2016. Analisis Perubahan Tutupan Lahan Manggrove di Kabupaten Seram Bagian Barat Maluku. Jurnal Hutan Pulau-pulau Kecil 1: 22 27.

Pattilouw I. R, Mardiatmoho. G, Puturuhu F. 2019. Analisis Perubahan Tutupan Lahan Hutan Di Iuphhk-Ha Pt. Gema Hutan Lestari Kabupaten Buru Provinsi Maluku. Jurnal Hutan Pulau-pulau Kecil 3: $127-135$.

Rochmayanto. dkk. 2014 Sintesis Penelitian Integratif Pengembangan Perhitungan Emisi Gas Rumah Kaca Kehutanan (Inventory). Kementerian Lingkungan Hidup Dan Kehutanan Badan Penelitian 
Dan Pengembangan Kehutanan Pusat

Penelitian Dan Pengembangan

Perubahan Iklim Dan Kebijakan, Bogor.

Setiyono B. 2006. Deteksi Perubahan Penutupan Lahan Menggunakan Citra Satelit Landsat ETM+ di Daerah Aliran Sungai (DAS) Juwana. Jawa Tengah. [Skripsi] Bogor (ID): Institut Pertanian Bogor.

Taofiqurohman. 2003. Analisis Perubahan Tutupan Lahan Terhadap Luas Sedimen Tersuspensi Di Perairan Berau, Kalimantan Timur Fakultas Peikanan dan Ilmu Kelautan Universitas Padjadjaran Jatinangor. Bandung.

Yusuf. S. M, dkk. 2018. Perubahan Spasial Tutupan Lahan Di DAS Citarum Hulu. Jurnal Pengelolaan Sumberdaya Alam dan Lingkungan. Institut Pertanian Bogor. Hal 8.3: 365 - 375 .

Wiske Rotinsulu. 2018. Analisis Perubahan Tutupan Lahan Das Tondano, Sulawesi Utara Selama Periode Tahun 2002 Dan 2015. Jurnal Pengelolaan Sumberdaya Alam dan Lingkungan. Institut Pertanian Bogor. Hal 8.3: 161 - 169 